
\title{
R Research Soure \\ The Role Of Apelin And Protamine Sulphate In Bile Duct Ligation Induced Liver Fibrosis In Rats
}

Suzan M. M. Moursi

Faculty of Medicine-Zagazig University

Eman El Bahaie

Faculty of Medicine-Zagazig University

Amira M. Abdelhamid ( $\Delta$ dr_mero_1985@yahoo.com )

Zagazig University https://orcid.org/0000-0002-0880-3137

Sherein F. El-sayed

Faculty of Medicine-Zagazig University

\section{Research Article}

Keywords: cholestasis, cirrhosis, apelin, inflammation.

Posted Date: February 14th, 2022

DOI: https://doi.org/10.21203/rs.3.rs-1346097/v1

License: (a) This work is licensed under a Creative Commons Attribution 4.0 International License.

Read Full License 


\title{
THE ROLE OF APELIN AND PROTAMINE SULPHATE IN BILE DUCT LIGATION INDUCED LIVER FIBROSIS IN RATS
}

\author{
Running title: APELIN, PROTAMINE SULPHATE AND LIVER FIBROSIS.
}

Suzan M. M. Moursi' ${ }^{1}$, Eman El Bahaie², Amira M. Abdelhamid ${ }^{3}$, Sherein F. El-sayed ${ }^{1}$

1: Physiology Department, Faculty of Medicine-Zagazig University, Egypt.

2: Zoology Department, Faculty of Science-Zagazig University, Egypt.

3: Clinical pharmacology Department, Faculty of Medicine-Zagazig University, Egypt.

\section{Author Details:}

Suzan Mohammed Mohammed Moursi, MD, Associate professor of physiology Department, Zagazig University, Zagazig, Egypt, E mail: $\underline{\text { Suzan_moursi@yahoo.com. }}$

Orcid No: 0000-0001-6796-3045.

Eman Said El Bahaie, MD, Lectuter of Zoology Department, Faculty of Science, Zagazig University, Zagazig, Egypt, E mail: e.elbahaie@yahoo.com.

Orcid No: 0000-0002-6422-5431

Amira Mohamed Abdelhamid, MD, lecturer of clinical pharmacology Department, faculty of Medicine, Zagazig University, Zagazig, Egypt, E mail: dr_mero_1985@yahoo.com.

Orcid No: 0000-0002-0880-3137

Sherein Fathy El-sayed, MD, lecturer of physiology Department, Zagazig University, Zagazig, Egypt, E mail: dr_sfathy@hotmail.com.

Orcid No: 0000-0002-6739-525X

\section{The corresponding author details}

\section{Amira Mohamed Abdelhamid}

Postal address: clinical pharmacology Department, Zagazig University.

Zagazig, sharkia, Egypt

Tel: +20552336364 - 00201017280852

Contact E mail: dr_mero_1985@yahoo.com.

Institutional email:AMAbdelhamid@medicine.zu.edu.eg.

\section{Acknowledgment:}

To Professor Ali Kh. Asalah; Physiology department, Faculty of Medicine, Zagazig University; for participating in choosing the research idea and preparation of the practical protocol and to Professor Kamal EL Kashishy; Pathology department, Faculty of Medicine, Zagazig University; for doing the histopathological examination. 


\section{ABSTRACT}

Purpose: This study was designed to investigate the effectiveness of protamine sulphate as an apelin receptor blocker on cholestatic liver fibrosis persuaded by common bile duct ligation (BDL) in experimental rats and examine some related mechanisms. Methods: Three groups of adult male Wistar rats were included: control (sham-operated), BDL and BDL+ protamine sulphate groups. All groups were examined after 4 weeks for serum apelin, total bilirubin, aspartate aminotransferase (AST), alanine aminotransferase (ALT), alkaline phosphatase (ALP), hepatic interleukin-6 (IL-6), tumor necrosis factor-alpha (TNF- $\alpha$ ), superoxide dismutase (SOD), glutathione peroxidase, (GPx) malondialdehyde (MDA), transforming growth factor- $\beta$ (TGF- $\beta$ ) and hydroxyproline content and for extracted livers histopathological studies. Results: BDL significantly increased serum apelin, total bilirubin, AST, ALT, ALP, hepatic IL-6, TNF- $\alpha$, MDA, TGF- $\beta$ and hydroxyproline content, but it significantly reduced serum albumin level and hepatic GPX and SOD activities. Serum level of apelin significantly revealed positive correlations with TNF- $\alpha$, MDA, TGF- $\beta$ and hydroxyproline content. On the other hand, protamine sulphate significantly attenuated these changes, with no effect on either serum apelin or bilirubin levels, in treated group. It also improved the hepatic histopathological changes. Conclusion: Protamine sulphate, may be through its apelin receptor blockade, ameliorated cholestatic liver injury, inflammation, and fibrosis induced by BDL.

Key words: cholestasis, cirrhosis, apelin, inflammation. 


\section{INTRODUCTION}

Hepatic cirrhosis is commonly the terminal pathology of chronic liver maladies. Pathologically, hepatic cirrhosis is characterized by sustained fibrillar deposition of extracellular matrix, parenchymal remodeling and formation of regenerative nodules, angiogenesis, and sinusoidal remodeling, inducing portal hypertension that eventually lead to liver failure (Ernández-Iglesias and Gracia-Sancho 2017).

Patients with liver cirrhosis develop a series multiple organ derangement which include renal failure, variceal hemorrhage, and spontaneous bacterial peritonitis making prognosis of hepatic cirrhosis is frustrating unless those patients benefit from liver transplant. (Russo et al. 2012). Among the various causes of liver fibrogenesis and cirrhosis, the incidence associated with hepatic cholestasis has been increasing globally in recent years, becoming a major public health concern (Li et al. 2018).

Cholestasis is the impairment of bile flow that can be classified upon the level of obstruction into intrahepatic or extrahepatic cholestasis and triggers nonspecific cellular damage, which provokes inflammation and a progressive hepatic fibrogenic disorders with cirrhosis and hepatocellular carcinoma in the advanced stage (Abshagen et al. 2015). Bile duct ligation (BDL) is the most used model, induced experimentally, for cholestatic liver injury, which leads to a similar phenotype as in human cholestasis (Bosoi et al. 2017).

There is an urgent requirement for more effective treatments to protect against liver cholestasis especially for patients unfavorably respond to ursodeoxycholic acid (the primary typical treatment for liver cholestasis for example obstructive cholestasis and primary biliary cirrhosis) (Sánchez-Salgado et al. 2019; Samant et al. 2019).

Apelin is a small peptide and endogenous ligand for the orphan G protein-linked receptor APJ, which is structurally correlated to angiotensin II type 1 receptor (AT1) (O'Carroll et al. 2013). The apelin/APJ is broadly distributed in heart, kidney, gastrointestinal tract, pancreas and hepatic parenchymal, endothelial, Stellate and Kupffer cells (Kwon et al. 2013).

Melgar-Lesmes et al. (2011) stated that apelin play a role in inflammation and angiogenesis. Apelin could provoke vascular growth in absence of vascular endothelial growth factor (VEGF) and its expression is controlled by TNF- $\alpha$. Moreover, apelin and APJ have an extensive distribution in hepatocytes of both rat and human cirrhotic liver that may produce important effects on liver function (Principe et al. 2008). Furthermore, Chen et al. (2013) has reported that the liver apelin/APJ system is also stimulated in biliary atresia progression, particularly in terminal stage of cirrhosis and the apelin mRNA expression significantly correlates with the degree of hepatic fibrosis.

Apelin/APJ axis may act as a novel probable therapy for hepatic diseases (Lv et al. 2017). Reichenbach et al. (2012) reported that Apelin/APJ system blockade has been shown to prevent progression of fibrosis in carbon tetrachloride treated rats. However, up to our knowledge, there is no information about the effectiveness in hepatic cholestasis. 
Few antagonists of apelin receptor have been recognized at this time. The peptide analog; apelin F13A was firstly exhibited inhibition of apelin 13 induced reduction in splanchnic neovascularization and blood pressure (Lee et al. 2005). Recently, the United States Food and Drug Administration (FDA) approved protamine as an antagonist for the APJ receptor (Le Gonidec et al. 2017).

Protamine is a basic protein which reverses the anticoagulant effect of heparin after invasive vascular procedures. Protamine also behaves as a full antagonist for apelin receptor and completely blocks apelin induced activation of $\mathrm{G}$-protein and recruitment of $\beta$-arrestin and can represent a hopeful drug for treatment of various diseases that are accompanied with neo-angiogenesis (Le Gonidec et al. 2017).

So, the current study was designed to determine the level of apelin and the effects of protamine sulphate administration as an apelin receptor blocker on hepatic injury and fibrosis induced experimentally by bile duct ligation in rats.

\section{MATERIAL \& METHODS}

\section{Ethical Approval}

All experimental procedures were reviewed and approved according to the guiding standard for the handling of research animals by means of ZU-IACUC committee, (protocol No: ZU-IACUC/ 3/ F/ 26/ 2021, 25th February 2021. The animals care was consistent with the Guide for the Care and Use of Laboratory Animals (8th edition, National Academies Press).

\section{$>$ Animal welfare}

The study was carried out in Faculty of Medicine, Zagazig University and implied thirty adult healthy male Wistar rats weighing 211-232 gm, 8-10 weeks old, obtained from the animal house at Faculty of Veterinary Medicine. Rats were housed under hygienic conditions in wired cages (5/cage) and kept on a natural light-dark cycle with free access to standard diet and water. Rats were subjected to one week of acclimatization to the new environment before the experiment was conducted.

Rats were randomly and equally assigned to three groups: group (I): sham-operated control group, group (II): bile duct ligation (BDL) group, and group (III): BDL treated group received a daily intravenous protamine sulphate (PROTAM vial 10mg/ml, Eipico Co, Egypt) diluted in saline, at a dose of $1.6 \mathrm{mg} / \mathrm{kg}$ (Liu et al. 2009). The administration of protamine sulphate started from the first day of BDL and continued for 4 weeks. Both group I and group II received saline ( $1 \mathrm{ml} / \mathrm{kg} /$ day) as a vehicle.

\section{$>$ Bile duct ligation procedure}

Each rat was weighed and anesthetized by administration of sodium thiopental $(50 \mathrm{mg} / \mathrm{kg})$ intraperitoneally. A midline laparotomy was done after the area was shaved and prepared by $10 \%$ povidone iodine solution. Exposure of the common bile duct by carefully dissecting it from the surrounding tissue was performed and then subjected to double ligation with 4-0 silk suture and transected between the ligatures. After that, abdominal layers were carefully closed by suturing the peritoneum, muscle layers and the skin wound. In the control sham operated rats, the common bile ducts were subjected to similar dissection and manipulation, but without any 
ligation (Zhou et al. 2014; Liu et al. 2017). Rats were injected with penicillin G (100,000 units I.M.) for 3 days postoperatively and Ketoprofen (Ketofen®) $5 \mathrm{mg} / \mathrm{kg}$ SC once every 24 hours.

\section{Sample collection:}

Four weeks after BDL, retro-orbital venous plexus blood samples were obtained after an overnight fasting under anesthesia with $50 \mathrm{mg} / \mathrm{kg}$ sodium thiopental i.p by the procedures described by Slododa et al. (1981).then serum was separated by allowing the blood samples to clot then centrifuged 20 minutes at 3,000 revolutions per minute, kept at $\left(-20^{\circ} \mathrm{c}\right)$ and used to measure the serum levels of apelin, AST, ALT, ALP, albumin and total bilirubin.

\section{$>$ Biochemical Analysis}

Serum apelin was assessed consistent with the manufacturer's directions using rat apelin ELISA kit (Shanghai Crystal Day Biotech Co., Ltd., Catalog Number E0813Ra).

Alanine aminotransferase and aspartate aminotransferase serum levels were assessed consistent with Rec (1970), using rat ALT \& AST ELISA kits (Shanghai Sunred biological technology, China).

Serum Alkaline Phosphatase level was estimated as described by Belfield and Goldberg (1971), using alkaline phosphatase assay kit (Sigma-Aldrich Co).

Serum albumin level was estimated as described by Stoskopf (1993).

Total bilirubin: was measured as described by Walters and Gerarde (1970).

\section{$>$ Tissue sampling:}

Following blood samples collection, rats were euthanized immediately via cervical dislocation, then total hepatectomies were performed and livers were divided into right, median and caudate lobes and left lobes then washed with phosphate buffered saline ( $\mathrm{pH}$ 7.4) and portions of the livers (right, median and caudate lobes) were homogenized as described by Firat et al. (2017) and stored at $-70^{\circ} \mathrm{C}$ for biochemical estimations of IL-6, TNF- $\alpha$, MDA, SOD and GPx activities, also estimation of TGF- $\beta$ and hydroxyproline content. The other portions (left lobes) were used for histopathological studies.

Hepatic TNF- $\alpha$ and IL-6 levels were estimated as described by Engvall and Perlmann (1971) and Fernando et al. (1998) using specific rat TNF- $\alpha$ and IL-6 ELISA Kits (Cat. No RAB0312 and RAB0480 respectively, Sigma-Aldrich Co.) following their manufacturers' recommendations.

Hepatic MDA were calculated using Lipid peroxidation -586 Colorimetric Assay kit (BIOXYTECH, OXIS Research, USA) consistent with the method of Gerard-Monnier et al. (1998).

Hepatic SOD and GPx: These markers of oxidative stress were measured using specific kits (BIOXYTECH, OXIS Research, USA) according to Nebot et al. (1993), and Ursini et al. (1982) methods, respectively.

Hepatic TGF- $\boldsymbol{\beta}$ was estimated by a commercial ELISA kit (Sigma Chemical Co.) as described by the manufacturer's instructions.

Hepatic Hydroxyproline content was assessed by means of hydroxyproline colorimetric assay kit (Sigma Chemical Co.) as described by Jamal et al. (1981). 


\section{$>$ Histopathological examination}

The left lobes of the excised livers were preserved in $10 \%$ formalin for 24 hours, dehydrated by putting them in increasing concentrations of ethanol baths and then infiltrated with paraffin wax. Parallel sections were cut with 5 - $\mu \mathrm{m}$ thickness and mounted on glass slides. Sections were dewaxed in xylene, hydrated through descending grades of ethanol to water and stained with Hematoxylin and Eosin (H\&E) and Masson's trichrome stains (Altunkayna 2005). Histopathological examination was done by an expert pathologist who had not known any information about animal grouping.

\section{$>$ Morphometric analyses}

Ten rats for each group were used for morphometric study using Image J software.

H\&E-stained sections of rat liver of the various studied groups was analysed to evaluate the inflammation of the portal tract that graded as none, mild, moderate, and severe (0-3). None: no portal inflammation, mild: (sprinkling of inflammatory cells in 1/3 of portal tracts), moderate: (increased inflammatory cells in 1/3-2/3 of portal tracts) or marked (dense packing of inflammatory cells in $>2 / 3$ of portal tracts) (Alsemeh et al. 2019).

Masson's Trichrome -stained slides of liver sections of different studied groups were analysed for calculation of the $\%$ area of collagen fibres distribution for periportal fibrosis that scored as $0: 2.1 \%, 1: 2.8 \%, 2: 4.3 \%, 3$ : 4.8\%, 4: 12.3\%) (Alsemeh et al. 2019).

\section{$>$ Statistical Analysis:}

Results were handed out as mean \pm standard deviation (SD). Data were compared using one-way analysis of variance (ANOVA) followed by least significant differences (LSD) post Hoc test to compare statistical differences between groups using SPSS program version 19 (SPSS Inc, Chicago, IL). Pearson's correlation coefficient test was performed to measure the statistical correlation between apelin level and other parameters. A p-value $\leq 0.05$ was addressed as statistically significant. Statistical analysis by Chi square test was done to evaluate the histopathological scoring of inflammation in the different studied groups.

\section{RESULTS}

Our study demonstrated that bile duct ligation (group-II) significantly elevated serum apelin, AST, ALT, ALP and total bilirubin, increased also hepatic IL-6, TNF- $\alpha$, MDA, TGF- $\beta$ and hydroxyproline content (P-value $<0.001$ ), but reduced significantly serum albumin level and hepatic SOD and GPx activities when compared to control group (group I) (P-value < 0.001) (figures 1(A-F)). Furthermore, apelin level showed significant positive correlations with TNF- $\alpha$, MDA, TGF- $\beta$ and hydroxyproline content (figures 2 (A-D) respectively).

Whereas, protamine sulphate significantly decreased serum AST, ALT, ALP and hepatic IL-6, TNF- $\alpha$, MDA, hydroxyproline (P-value < 0.001) and TGF- $\beta$ levels (P-value < 0.01), but it significantly increased serum albumin level, and hepatic SOD (P-value < 0.001) and GPx activities (P-value < 0.01) with no significant effect on serum total bilirubin or apelin levels (P-value > 0.05) when compared to BDL group (group II) (figures 1(AF). 
H\&E-stained sections of liver tissue from the control group revealed normal liver architecture (Figure 3 (A, B), Table (1)). Moreover, histopathological examination revealed hepatic injury in the BDL rats (group II) as indicated by the disturbed normal appearance of hepatocytes architecture with disruption of the continuity of its endothelial lining, heavy cellular infiltrations (marked inflammation) around the proliferated bile ducts and dilated congested portal vein (Figure $4(\mathbf{A}-\mathbf{C})$, Table (1)). All these changes were reduced by protamine sulphate administration in (group III) (Figure 5 (A, B), Table (1).

Masson-stained liver sections detected a normal distribution of collagen fibers in the portal area in the control groups (Figure 6 a), abundant collagen fibers around portal vein, bile ducts and in between hepatocytes in BDL group (Figure 6 b); but these changes were ameliorated by protamine sulphate administration (Figure 6 C). Statistical analysis of the \% area of stained collagen fibres in the BDL group was significantly higher than the control group, in contrast, administration of protamine revealed a significant decrease in the $\%$ area of collagen distribution compared to BDL but still exhibited a significant difference compared to control group $(\mathrm{P}<0.05)$ as shown in (Figure $6 \mathbf{d}$, table 2$).$

\section{DISCUSSION}

Liver fibrosis is a major hepatological outcome of most chronic hepatic injuries including cholestatic liver diseases. A rat model of bile duct ligation is an ideal model of biliary cholestasis in animals and commonly used to understand the pathogenesis of cholestatic liver fibrosis and to investigate the anti-hepatofibrotic therapies (Jüngst and Lammert 2013).

The hepatic apelin/ APJ system is activated in cirrhosis suggesting the direct relationship between apelin expression and profibrogenic factors in hepatic stellate cells (HSCs) (Chen et al. 2013).

Accordingly, the current study was planned to investigate the effect of protamine sulphate as an APJ receptor blocker on liver fibrosis induced by BDL in rats.

The results of our study revealed a significantly increased serum apelin level in BDL rats compared to normal one. This is in agree with the results of Chen et al. (2013) which reported activated apelin mRNA expression in hepatic fibrosis progression in biliary atresia. Principe et al. (2008) and Lim et al. (2016) also reported increased apelin circulating levels in cirrhotic patients. In contrast, Owen et al. (2020) found reduced apelin level in patients with both early-stage fibrosis and late-stage cirrhosis hepatic diseases. Moreover, protamine sulphate administration to BDL rats in group III produced no significant change in apelin level compared to BDL untreated rats.

In the current study, liver injury is noticed by histopathological examination in BDL rats as indicated by disturbed liver cells architecture and wide inflammatory cells infiltration around the proliferated bile ducts. Collagenous bands also accumulated considerably in BDL rats (stained blue in Masson's trichrome staining). The demonstrated histopathological changes were combined with significantly increased serum ALT, AST and ALP levels and a significant reduction in serum albumin level. In addition, serum total bilirubin level was significantly increased due to BDL. These results are in agree with the findings of Teixeira et al. (2013) and Kim et al. (2015).

Hepatic cellular injury recruit inflammatory and immune cells with production of specific cytokine and growth factors that trigger trans-differentiation of quiescent hepatic stellate cells (HSC) to myofibroblast-like cells and 
promote inflammatory response and angiogenesis (Tsuchida and Friedman 2017). Chronic liver injury, inflammation, and regenerative changes result in widespread distortion of normal hepatic architecture and perpetuate fibrosis of parenchyma that eventually leads to cirrhosis and hepatocellular carcinoma (Cordero-Espinoza and Huch 2018).

Noteworthy, the present study demonstrated that liver cell injury and fibrosis were significantly ameliorated by protamine sulphate administration as indicated by differences in the degree of hepatocytes disruption, inflammatory cellular infiltration, and collagen bands deposition in hepatic tissue in the treated group. The significantly decreased ALT, AST and ALP serum levels and the significantly increased serum albumin level also indicate reduced hepatocytes injury, which is consistent with the histopathological analysis suggesting the beneficial effect of protamine sulphate administration.

It has been notified that bile duct ligation decreases antioxidant defenses and elevates free radicals' production that play a role in hepatic fibrogenesis either by reacting directly or via lipid peroxidation (Tahan et al. 2007). Obstruction of bile flow stimulate Kupffer cells and overwhelming activation of neutrophils that release ROS and proteases responsible for the induced oxidative stress damage (Datta et al. 2013).

In agreement with the previous studies, significantly elevated liver MDA content (an end-product of lipid peroxidation) associated with significant decreases in liver SOD and GPx activities were demonstrated in BDL rats in our study. Our results also disseminated that BDL significantly increased hepatic TNF- $\alpha$ and IL-6. Inflammation has an important role in the development of obstructive jaundice induced hepatic injury. BDL prompted cell death and $\mathrm{NF} \kappa \mathrm{B}$ activation that led to proinflammatory cytokines release, leukocytes infiltration and additional spurt of oxidative stress (Zhou et al. 2014).

Our study also showed significant positive correlations between serum apelin and hepatic TNF- $\alpha$ and MDA in the BDL group. García-Díaz et al. (2007) also revealed a significant direct correlation between liver MDA level and subcutaneous apelin gene expression in nonalcoholic fatty liver disease (NAFLD) rats. Apelin promotes expression and production of vascular cell adhesion molecule 1 (VCAM-1), monocyte chemoattractant protein 1 (MCP-1) and intercellular adhesion molecule 1 (ICAM-1) through NF- $\kappa$ B and c-jun N-terminal kinase (Jnk) signaling pathways (Lu et al. 2012). Lv et al. (2013) also reported the roles of apelin-APJ system in oxidative stress and endothelial inflammation associated atherosclerosis. Nevertheless, by contrast, apelin was able to attenuate ROS production in adipocytes (Than et al. 2014), cardiomyocytes (Foussal et al. 2010) and hepatic ischemia- reperfusion injury rats (Sagiroglu et al. 2014). A possible explanation for these opposing effects could be the existence of diverse isoforms of apelin (Zhou et al. 2016).

Results of the current study also demonstrated an increase in hepatic TGF- $\beta$ and hydroxyproline content in the BDL rats. In biliary fibrosis, hepatic stellate cells (HSCs) transdifferentiate from a quiescent lipid and retinoid storing pericytes in the perisinusoidal space to a myofibroblast like phenotype secreting extracellular-matrix proteins via the release of fibro-genic cytokines, including TGF- $\beta$. TGF- $\beta$ is a master profibrogenic cytokine that can promote direct activation of HSCs and induce platelet-derived growth factor $\beta$ (PDGF- $\beta$ ) and connective tissue growth factor (CTGF) receptors expression in the liver resulting in extracellular matrix production (Kisseleva and Brenner 2007). Overabundant deposition of extracellular matrix proteins such as type I collagen distorts the normal hepatic architecture by forming a thick web of interconnecting fibrous scars (Erenoğlu et al. 2011).

Hydroxyproline is a major constituent of fibrillar collagen formed by hydroxylation of proline by 4-prolyl hydroxylase enzyme. It plays a crucial role for collagen stability and its level in hepatic tissue, blood, and urine is linked to the rate of liver fibrosis progression (Gabr et al. 2016). The hepatic architectural changes 
result from combined increased synthesis of cytoskeletal proteins and failure of breaking down such proteins, leading to progressive fibrogenesis that ultimately progresses to cirrhosis (Svegliati-Baroni et al. 2008).

Additionally, the current study showed significant positive correlations between liver TGF- $\beta$ and hydroxyproline content and serum apelin level in the BDL group. Marei et al. (2020) also reported a significant positive correlation between the extent of fibrosis in chronic hepatitis $\mathrm{C}$ patients and apelin level and confirmed the apelin role in the disease progression.

TNF- $\alpha$ increased the expression of apelin/APJ in hepatic cells that contribute to angiogenesis, HSCs activation, and ultimately, hepatic fibrosis (Ying et al. 2017). Apelin has revealed a great potential for promotion of hepatic fibrosis. It acts directly on LX-2 cells (a cell line has same characteristics of hepatic stellate cells) through extracellular signal-regulated kinases (Erk) signaling, enhancing its survival and PDGF- $\beta$-receptor and collagen synthesis in these cells. PDGF- $\beta$ can also enhance apelin receptor expression and stimulate HSCs activation (Wang et al. 2019).

Conversely, APJ blockade by F13A (an APJ antagonist) inhibited angiogenesis, cell infiltration and collagen deposition in $\mathrm{CCl}_{4}$-treated rats (Reichenbach et al. 2012). Similarly, treatment with protamine sulphate (as a full antagonist for APJ) significantly reduced oxidative stress, inflammatory markers, and hepatic levels of TGF- $\beta$ and hydroxyproline content in the cholestatic injury model in our study. Protamine has been noted to bind fibroblast growth factor (FGF) and PDGF tyrosine kinase receptors to attenuate fibroblasts mitogenesis and it also has antiangiogenic effects in different models of cancer (Le Gonidec et al. 2017).

\section{Conclusions}

In summary, It has been postulated that liver apelin/APJ system could play a major role in the perpetuation and progression of inflammation and fibrogenesis taking place in fibrotic liver and a new pharmacologic property of protamine sulphate has been demonstrated in this study, and seems to be an effective method to improve liver injury and fibrosis in cholestatic liver injury as settled by the significantly diminished ALT, AST and ALP serum levels, increased serum albumin, decreased hepatic profibrogenic markers (TGF- $\beta$ and hydroxyproline) and the improved liver histopathology.

Further studies to investigate the mechanisms implicated in the consequence of apelin-APJ signaling in hepatic diseases are essential to be examined and to determine whether apelin receptor antagonists (including protamine sulphate) could be used as a new therapeutic method in humans with liver diseases or undergoing surgery.

\section{Ethics declarations}

\section{Ethical approval}

The Ethical committee for scientific research of faculty of Medicine, Zagazig university, Egypt approved this experimental study.

\section{Consent to participate}

All authors consent to participate.

\section{Consent for publication}

All authors consent to the publication of this paper. 
Authors' contributions: S.M.M., E.E.B and S.E.F planned for the study. S.M.M., S.E.F. and A.M.A. carried out the experiment. A.M.A. and S.M.M. analyzed the data. S.M.M., E.E.B. and S.E.F. wrote the manuscript. All authors read and approved the manuscript. The authors declare that all data were generated in-house and that no paper mill was used.

\section{Funding:}

This research received no specific grant from any funding agency in the public, commercial, or not-for-profit sectors.

Conflict of interest: No conflicts of interest reported.

Data availability statement

All data that support the results in the article are available as mean \pm SD values, as well as statistical summaries as supporting information.

\section{REFERENCES}

1. Abshagen K, König M, Hoppe A, Müller I, Ebert M, Weng H, Holzhütter H-G, Zanger U.M, Bode J, Vollmar B, Thomas M \& Dooley S (2015) Pathobiochemical signatures of cholestatic liver disease in bile duct ligated mice. BMC Syst. Biol 9 (83). https://doi: 10.1186/s12918-015-0229-0.

2. Alsemeh A.E, Moawad R.S \& Abdelfattah E.R (2019) Histological and biochemical changes induced by gibberellic acid in the livers of pregnant albino rats and their offspring: ameliorative effect of Nigella sativa. Anatomical science international 94(4), 307-323. https://doi: 10.1007/s12565-019-00488-0.

3. Altunkaynak $\mathbf{Z}$ (2005) Effect of high fat diet induced obesity on female rat livers (A histochemical study). Eur.J.Gen.Med 2(3):100-109. https://doi.org/10.29333/ejgm/82319

4. Belfield A \& Goldberg D.M (1971) Hydrolysis of adenosine monophosphates by acid phosphatases as measured by a continuous spectrophotometric assay. Biochem. Med 4: 135-148. https://doi: 10.1016/00062944(70)90090-6.

5. Bosoi C.R, Oliveira M.M, Ochoa-Sanchez R, Tremblay M, Ten Have G.A, Deutz N.E, Rose C.F, and Bemeur C (2017). The bile duct ligated rat: A relevant model to study muscle mass loss in cirrhosis. Metab. Brain Dis 32: 513-518. https://doi: 10.1007/s11011-016-9937-4.

6. Chen W, Oue T, Ueno T, Uehara S, Usui N \& Fukuzawa M (2013). Apelin is a marker of the progression of liver fibrosis and portal hypertension in patients with biliary atresia. Pediatr Surg Int 29:79-85. https://doi: 10.1007/s00383-012-3210-7

7. Cordero-Espinoza L \& Huch M (2018) The balancing act of the liver: Tissue regeneration versus fibrosis. J. Clin. Investig 128: 85-96. https://doi: 10.1172/JCI93562

8. Datta G, Fuller BJ \& Davidson BR (2013) Molecular mechanisms of liver ischemia reperfusion injury: insights from transgenic knockout models. World J Gastroenterol 19(11):1683-98. https://doi: 10.3748/wjg.v19.i11.1683

9. Engvall E \& Perlmann P (1971) Enzyme-linked immunosorbent assay (ELISA). Quantitative assay of immunoglobulin G. Immunochemistry 8(9): 871-874. https://doi: 10.1016/0019-2791(71)90454-X

10. Erenoğlu C, Kanter M, Aksu B, Sağıroğlu T, Ayvaz S, Aktaş C \& Erboğa M (2011) Protective Effect of Curcumin on Liver Damage Induced by Biliary Obstruction in Rats. Balkan Med J 28: 352-357. https:// doi: $10.5174 /$ tutfd.2010.04312.1

11. Ernández-Iglesias A \& Gracia-Sancho J (2017) How to face chronic liver disease: the sinusoidal perspective. Front Med 4:7. https:// doi: 10.3389/fmed.2017.00007 
12. Fernando B, Marley R, Holt S, Anand R, Harry D, Sanderson P, Smith R, Hamilton G \& Moore K (1998) $\mathrm{N}$-acetylcysteine prevents development of the hyperdynamic ciculation in the portal hypertensive rat. Hepatology 28(3):689. https:// doi: 10.1002/hep.510280314

13. Firat O, Makay O, Yeniay L, Gokce G, Yenisey C \& Coker A (2017) Omega-3 fatty acids inhibit oxidative stress in a rat model of liver regeneration. Ann Surg Treat Res 93(1):1-10. https:// doi: 10.4174/astr.2017.93.1.1

14. Foussal C, Lairez O, Calise D, Pathak A, Guilbeau-Frugier C, Valet P, Parini A \& Kunduzova O (2010) Activation of catalase by apelin prevents oxidative stress-linked cardiac hypertrophy. FEBS Lett 584: 2363 2370. https://doi.org/10.1016/j.febslet.2010.04.025

15. Gabr S.A, Alghadir A.H, Sherif Y.E \& Ghfar A.A (2017). Hydroxyproline as a Biomarker in Liver Disease Biomarkers in Liver Disease 1-21. https://doi.org/10.1007/978-94-007-7675-3 26

16. García-Díaz D, Campión J, Milagro FI \& Martínez JA (2007) Adiposity dependent apelin gene expression: relationships with oxidative and inflammation markers. Mol Cell Biochem 305: 87-94. https://doi:10.1007/s11010-007-9531-5.

17. Gerard-Monnier D, Erdelmeier I, Regnard K, Moze-Henry N, Yadan JC \& Chaudiere J (1998) Reactions of 1-methyl-2-phenylindole with malondialdehyde and 4-hydroxyalkenals. Analytical applications to a colorimetric assay of lipid peroxidation. Chem Res Toxicol 11:1176-83. https://doi.org/10.1021/tx9701790

18. Jamal I.S, Finelli V.N \& Hee S.Q (1981) A simple method to determine nanogram levels of 4-hydroxyproline in biological tissues. Anal Biochem 112 (1): 70-75. https://doi: 10.1016/0003-2697(81)90261-X.

19. Jüngst $\mathbf{C} \quad \boldsymbol{\&}$ Lammert $\mathbf{F}$ (2013). Cholestatic liver disease. Dig Dis 31: $152-154$. https://doi.org/10.1159/000347210

20. Kim HG, Han JM, Lee JS, Lee JS \& Son CG (2015) Ethyl acetate fraction of Amomum xanthioides improves bile duct ligation-induced liver fibrosis of rat model via modulation of pro-fibrogenic cytokines. Sci Rep 28(5):14531. https://doi: 10.1038/srep14531.

21. Kisseleva T \& Brenner D. A (2007) Role of hepatic stellate cells in fibrogenesis and the reversal of fibrosis. J Gastroenterol Hepatol 22 (1): S73-78. https:// doi: 10.1111/j.1440-1746.2006.04584.X

22. Kwon M, Tuvshintur B, Kim W, Jin H, Yin G \& Song K (2013) Expression of the apelin-APJ pathway and effects on erectile function in a mouse model of vasculogenic erectile dysfunction J Sex Med 10 (12): 29282941. https://doi: 10.1111/jsm.12158

23. Le Gonidec S, Chaves-Almagro C, Bai Y, Kang H.J, Smith A, Wanecq E, Huang X.P, Prats H, Knibiehler B, Roth B.L, Barak L.S, Caron M.G, Valet P, Audigier Y \& Masri B (2017) Protamine is an antagonist of apelin receptor, and its activity is reversed by heparin. FASEB journal: official publication of the Federation of American Societies for Experimental Biology 31(6): 2507-2519. https://doi: 10.1096/fj.201601074R

24. Lee DK, Saldivia VR, Nguyen T, Cheng R, George SR \& O'Dowd BF (2005) Modification of the terminal residue of apelin-13 antagonizes its hypotensive action. Endocrinology 146(1):231-236. https://doi.org/10.1210/en.2004-0359

25. Li B, Zhang C \& Zhan Y.T (2018) Nonalcoholic Fatty Liver Disease Cirrhosis: A Review of Its Epidemiology, Risk Factors, Clinical Presentation, Diagnosis, Management, and Prognosis. Can J Gastroenterol Hepatol 2784537. https://doi:10.1155/2018/2784537. 
26. Lim Y, Choi E, Jang Y, Cho Y, Kang Y, Baik S, Kwon S.O\& Kim M.Y (2016) Clinical implications of the serum apelin level on portal hypertension and prognosis of liver cirrhosis. Gut Liver 10 (1): $109-116$. https://doi: 10.5009/gnl14345

27. Liu F, Chen L, Rao H.Y, Teng X, Ren Y.Y, Lu Y.Q, Zhang W, Wu N, Liu F.F \& Wei L (2017) Automated evaluation of liver fibrosis in thioacetamide, carbon tetrachloride, and bile duct ligation rodent models using second-harmonic generation/two-photon excited fluorescence microscopy. Laboratory Investigation; a Journal of Technical Methods and Pathology 97(1):84-92. https://doi: 10.1038/labinvest.2016.128.

28. Liu K.X, Kato Y, Kaku T.I, Matsumoto K, Nakamura T \& Sugiyama Y (2009) Characterization of the Enhancing Effect of Protamine on the Proliferative Activity of Hepatocyte Growth Factor in Rat Hepatocytes. Pharmaceutical Research.26 (4): 1012-1021. https://doi: 10.1007/s11095-008-9810-1.

29. Lu Y, Zhu X, Liang GX, Cui RR, Liu Y, Wu SS, Liang QH, Liu GY, Jiang Y, Liao XB, Xie H, Zhou HD, Wu XP, Yuan LQ \& Liao EY (2012) Apelin-APJ induces ICAM-1, VCAM-1 and MCP-1 expression via NFkappaB/JNK signal pathway in human umbilical vein endothelial cells. Amino Acids 43: 2125-2136. https://doi: 10.1007/s00726-012-1298-7

30. Lv D, Li H \& Chen L (2013) Apelin and APJ, a novel critical factor and therapeutic target for atherosclerosis. Acta Biochim Biophys Sin (Shanghai) 45: 527-533. https://doi.org/10.1093/abbs/gmt040

31. Lv SY, Cui B, Chen WD \& Wang YD (2017) Apelin/APJ system: A key therapeutic target for liver disease. Oncotarget 8(67):112145-112151. https://doi: 10.18632/oncotarget.22841

32. Marei E, Mohamed H \& Shaheen D (2020) Potential role of vaspin and apelin in chronic hepatitis $C$ virus patients with and without diabetes. Journal of Radiation Research and Applied Sciences 13. 155-163. https://doi.org/10.1080/16878507.2020.1715556

33. Melgar-Lesmes P, Pauta M, Reichenbach V, Casals G, Ros J, Bataller R, Morales-Ruiz M \& Jiménez W (2011) Hypoxia and proinflammatory factors upregulate apelin receptor expression in human stellate cells and hepatocytes. Gut 60:1404-11. https://doi: 10.1136/gut.2010.234690

34. Nebot C, Moutet M, Huet P, Xu JZ, Yadan JC \& Chaudiere J (1993) Spectrophotometric assay of superoxide dismutase activity based on the activated autoxidation of a tetracyclic catechol. Anal Biochem 214:442-51.https://doi: 10.1006/abio.1993.1521

35. O'Carroll A, Lolait S, Harris L \& Pope G (2013) The apelin receptor APJ journey from an orphan to a multifaceted regulator o Homeostasis. J Endocrinol 219 (1): 13-35. https://doi: 10.1530/JOE-13-0227

36. Owen N.E, Nyimanu D, Kuc R.E, Upton P, Morrell N.W, Alexander G.J, Maguire J.J \& Davenport A.P (2020) Plasma levels of apelin are reduced in patients with liver fibrosis and cirrhosis but are not correlated with circulating levels of bone morphogenetic protein 9 and 10. Peptides 136:170440. https://doi: 10.1016/j.peptides.2020.170440

37. Principe A, Melgar-Lesmes P, Fernández-Varo G, del Arbol L.R, Ros J, Morales-Ruiz M, Bernardi M, Arroyo V, and Jiménez W (2008) The hepatic apelin system: a new therapeutic target for liver disease. Hepatology 48:1193-201. https://doi: 10.1002/hep.22467

38. Rec JS (1970) Estimation of serum ALT. J. Clin. Biochem 8:658.

39. Reichenbach V, Ros J, Fernández-Varo G, Casals G, Melgar-Lesmes P, Campos T, Makriyannis, Morales-Ruiz M\& Jiménez W (2012) Prevention of fibrosis progression in CCl4-treated rats: role of the 
hepatic endocannabinoid and apelin systems. J Pharmacol Exp Ther 340:629-37. https://doi: 10.1124/jpet.111.188078

40. Russo L, Gracia-Sancho J, García-Calderó H, Marrone G, García-Pagán J.C, García-Cardeña G \& Bosch J (2012) Addition of simvastatin to cold storage solution prevents endothelial dysfunction in explanted rat livers. Hepatology 55:921-930. https://doi: 10.1002/hep.24755

41. Sagiroglu T, Aksoy M.B, Sagiroglu G, Tozkir H, Oguz S, Yalta T, Yagci M.A \& Sezer A (2014) Effect of leptin and apelin preconditioning on hepatic ischemia reperfusion injury in rats. Indian J Surg 76(2):111-6. https://doi: 10.1007/s12262-012-0676-4

42. Samant H, Manatsathit W, Dies D, Shokouh-Amiri H, Zibari G, Boktor M, \& Alexander JS (2019) Cholestatic liver diseases: An era of emerging therapies. World J Clin Cases 7(13): 1571-1581. https://doi: 10.12998/wjcc.v7.i13.1571

43. Sánchez-Salgado J. C, Estrada-Soto S, García-Jiménez S, Montes S, Gómez-Zamudio J \& VillalobosMolina R (2019) Analysis of Flavonoids Bioactivity for Cholestatic Liver Disease: Systematic Literature Search and Experimental Approaches. Biomolecules 9(3), 102.https://doi: 10.3390/biom9030102

44. Slododa A, Birnpaum J, Oronsky A, and Kerwar S (1981) Studies on type II collagen-induced polyarthritis in rats. Arthritis Rheum 24:616-624. https://doi.org/10.1002/art.1780240408

45. Stoskopf M.A (1993) Fish medicine. Sounders Company. U.S.A 882.

46. Svegliati-Baroni G, De Minicis S \& Marzioni M (2008) Hepatic fibrogenesis in response to chronic liver injury: Novel insights on the role of cell-to-cell interaction and transition Liver Int 28:1052-1064. https://doi: 10.1111/j.1478-3231.2008.01825.x

47. Tahan G, Tarcin O, Tahan V, Eren F, Gedik N, Sahan E, Biberoglu N, Guzel S, Bozbas A, Tozun N \& Yucel O (2007) The effects of N-acetylcysteine on bile duct ligation-induced liver fibrosis in rats. Dig Dis Sci 52: 3348-3354. https://doi: 10.1007/s10620-006-9717-9

48. Teixeira C, Franco E, Oliveira PA, Colaço B, Gama A, Carrola J, Pires CA, Colaço A \& Pires MJ (2013) Effects of nebivolol on liver fibrosis induced by bile duct ligation in Wistar rats. In Vivo 27(5):635-40. https://doi: 10.1177/0960327112474832.

49. Than A, Zhang X, Leow MK, Poh CL, Chong SK \& Chen P (2014) Apelin attenuates oxidative stress in human adipocytes. J Biol Chem 289: 3763-3774. https://doi: 10.1074/jbc.M113.526210

50. Tsuchida T \& Friedman S.L (2017) Mechanisms of hepatic stellate cell activation. Nat. Rev. Gastroenterol. Hepatol 14: 397-411. https://doi.org/10.1038/nrgastro.2017.38

51. Ursini F, Maiorino M, Valente M, Ferri L \& Gregolin C (1982) Purification from pig liver of a protein which protects liposome and biomembranes from peroxidative degradation and exhibits glutathione peroxidase activity on phosphatidylcholine hydroperoxides. Biochim Biophys Acta 710:197-211. https://doi: 10.1016/0005-2760(82)90150-3

52. Walters M.I \& Gerarde H.W (1970) An ultramicromethod for the determination of conjugated and total bilirubin in serum or plasma. Michrochem. J 15:231-243. https://doi.org/10.1016/0026-265X(70)90045-7

53. Wang Y, Song J, Bian H, Bo J, Lv S, Pan W \& Lv X (2019) Apelin promotes hepatic fibrosis through ERK signaling in LX-2 cells. Mol. Cell Biochem 460: 205-215. https://doi.org/10.1007/s11010-019-03581-0

54. Ying H.Z, Chen Q, Zhang W.Y, Zhang H.H, Ma Y, Zhang S.Z, Fang J \& Yu C.H (2017) PDGF signaling pathway in hepatic fibrosis pathogenesis and therapeutics. Mol. Med. Rep 16: 7879-7889. https://doi.org/10.3892/mmr.2017.7641 
55. Zhou Q, Cao J \& Chen L (2016) Apelin/APJ system: A novel therapeutic target for oxidative stress-related inflammatory diseases (Review). Int J Mol Med. 37(5):1159-69. https://doi.org/10.3892/ijmm.2016.2544

56. Zhou YX, Ni Y, Liu YB \& Liu X (2014) Histone preconditioning protects against obstructive jaundiceinduced liver injury in rats. Exp Ther Med 8(1):15-20. https://doi.org/10.3892/etm.2014.1697.

Table 1: Scores for hepatic cellular infiltration in different groups

\begin{tabular}{|c|c|c|c|c|c|c|c|}
\hline \multirow{2}{*}{ Cellular infiltration. } & \multicolumn{2}{|c|}{$\begin{array}{l}\text { Control } \\
\text { group }\end{array}$} & \multicolumn{2}{|c|}{ BDL group } & \multicolumn{2}{|c|}{$\begin{array}{c}\text { BDL group treated by } \\
\text { protamine sulfate }\end{array}$} & \multirow[t]{2}{*}{$\mathbf{p}^{\wedge}$} \\
\hline & $\overline{\mathbf{N}}$ & $\%$ & $\overline{\mathbf{N}}$ & $\%$ & $\overline{\bar{N}}$ & $\%$ & \\
\hline None (0) & 10 & 100 & $\mathbf{0}$ & $\mathbf{0}$ & 4 & 40 & \\
\hline Mild (1) & $\mathbf{0}$ & 0 & 4 & 40 & 6 & 60 & $0.000^{* *}$ \\
\hline Moderate (2) & $\mathbf{0}$ & $\mathbf{0}$ & 6 & 60 & $\mathbf{0}$ & $\mathbf{0}$ & \\
\hline Marked (3) & $\mathbf{0}$ & $\mathbf{0}$ & $\mathbf{0}$ & $\mathbf{0}$ & $\mathbf{0}$ & $\mathbf{0}$ & \\
\hline
\end{tabular}

** Statistically highly significant difference $(\mathrm{P} \leq 0.001)$, $\mathrm{n}$ : number (number of sacrificed rats in each group=10 rats), $\wedge=$ Chi-square test, \%: Percent.

There are statistically highly significant differences between all groups regarding all grades of histopathological changes.

Table 2: Scores for hepatic periportal fibrosis in different groups.

\begin{tabular}{|c|c|c|c|}
\hline Periportal fibrosis & Control group & BDL group & $\begin{array}{c}\text { BDL group treated by } \\
\text { protamine sulfate }\end{array}$ \\
\hline Mean \pm SD & $2.039 \pm \quad 0.7448$ & $12.34 \pm 1.333^{\mathrm{a}}$ & $4.727 \pm 1.783^{\mathrm{a}, \mathrm{b}}$ \\
\hline I value & & $P<0.05$ & $P<0.05$ \\
\hline
\end{tabular}

$(\mathrm{SD}=$ standard deviation $\quad \mathrm{a}=$ versus control group $\quad \mathrm{b}=$ versus BDL group).

Figure (1): showing A. Serum apelin level. B. Serum alanine aminotransferase (ALT), aspartate aminotransferase (AST) and alkaline phosphatase (ALP). C. Serum total bilirubin and albumin D. Liver transforming growth factor- $\beta$ (TGF- $\beta$ ) and Hydroxyproline content E. Hepatic TNF- $\alpha$ and IL-6 and F. Hepatic MDA, SOD and GPx of all studied groups. Values presented as mean $\pm \mathrm{SD}(\mathrm{n}=10) . \mathrm{P}<0.001$. Table $\mathrm{S} 1 \& \mathrm{~S} 2$

Figure (2): Showing the correlation between serum Apelin and hepatic A. TNF- $\alpha$ level B. MDA 
Level C. TGF- $\beta$ and D. hepatic hydroxyproline content in the BDL group.

Figure (3): Photomicrographs of hepatic tissues stained with H\&E of normal rats showing a. normal histoarchitecture of liver with closely packed polygonal hepatocytes cords having eosinophilic cytoplasm and round vesicular nuclei (arrowhead) with blood sinusoids (s) in between and radiated from the central vein $(\mathrm{CV})$, b. portal area containing a thin-walled portal vein (PV), normal bile duct (Bd) and hepatic artery (Ha) and normal hepatic cells with eosinophilic cytoplasm and round vesicular nuclei (arrowhead) separated by blood sinusoids (S) (H\&E X400).

Figure (4): Photomicrographs of hepatic tissues stained with H\&E of BDL rats showing a. disturbed liver cells histoarchitecture around the dilated central vein $(\mathrm{CV})$ with disruption of the continuity of its endothelial lining but with intact most hepatocytes that have vesicular nuclei (arrowhead). Most blood sinusoids (S) are dilated, b. the portal vein (PV) and profuse proliferated bile ducts (Bd) surrounded by heavy cellular infiltrations (asterisk) with disturbed normal appearance of hepatocytes but still show vesicular nuclei (arrowhead), c. markedly dilated congested portal vein with thick endothelial lining (short arrow), Proliferated bile ducts can be observed, most hepatocytes are normal (arrow heads), and few hepatocytes have darkly staining nuclei (bifid arrows) (H\&E X400).

Figure (5): Photomicrographs of hepatic tissues stained with H\&E of BDL rats treated with protamine sulphate showing a. nearly normal liver cells histoarchitecture around the dilated central vein $(\mathrm{CV})$ with less disruption of the continuity of its endothelial lining and most hepatocytes are intact with vesicular nuclei (arrowhead). Few dilated blood sinusoids (S) can also be observed, b. normal caliber of portal vein (PV) and less proliferated bile ducts (Bd) with less cellular infiltrations (asterisk). Most hepatocytes have vesicular nuclei (arrowhead). (H\&E X400).

Figure (6): Photomicrograph of hepatic tissues stained with Masson's tricrome showing a. fine collagen fibers distribution (arrow) around the bile duct (Bd) and portal vein (PV) in control rat. b. abundant collagen fibers distribution (arrow) around the portal vein, Bile duct and in between the hepatocytes in BDL rats C. Mild collagen fibers distribution (arrow) around the central vein and in between the hepatocytes in BDL rats treated with protamine sulphate. (Masson's trichome X200). d. Bar chart shows scores for periportal fibrosis in different groups. Values expressed as mean $\pm \mathrm{SD}(\mathrm{n}=10) . \mathrm{P}<0.05$ 


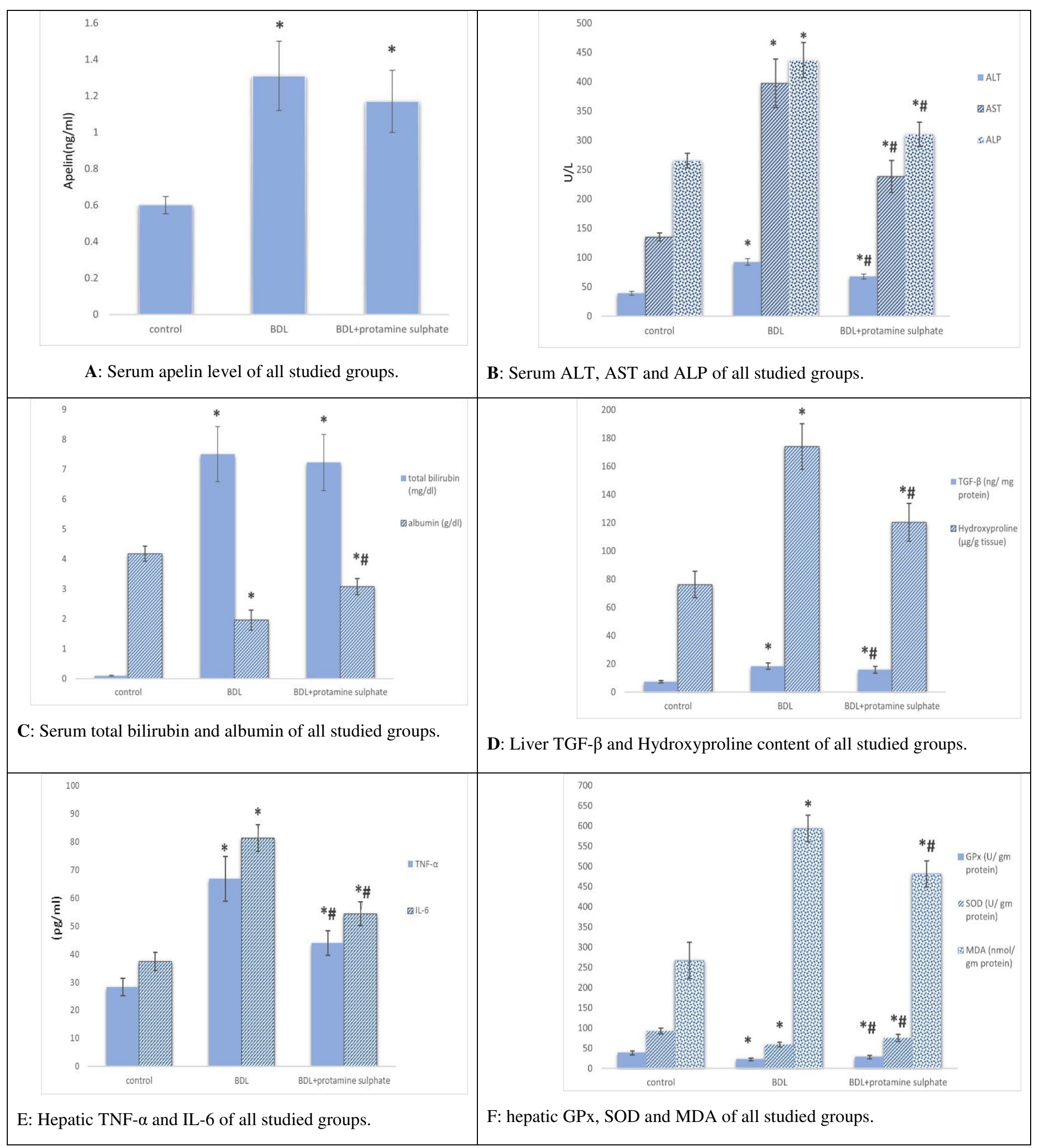

Figure (1):* (Significant versus control group), \# (significant versus BDL group) $\mathrm{P}<0.001$. 


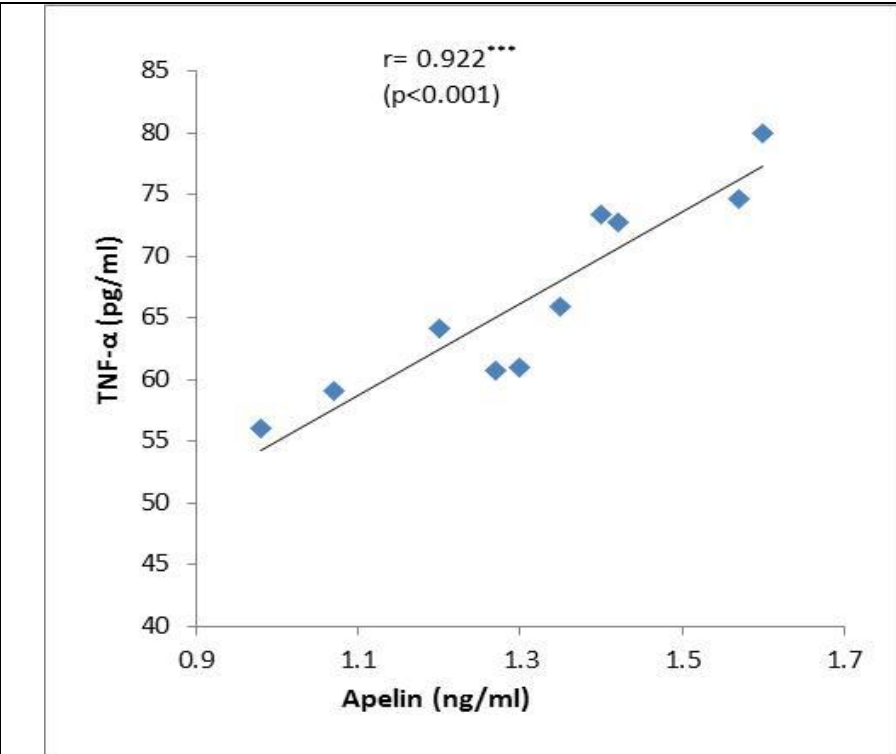

A: Correlation between serum Apelin and hepatic TNF- $\alpha$ levels in the BDL group.

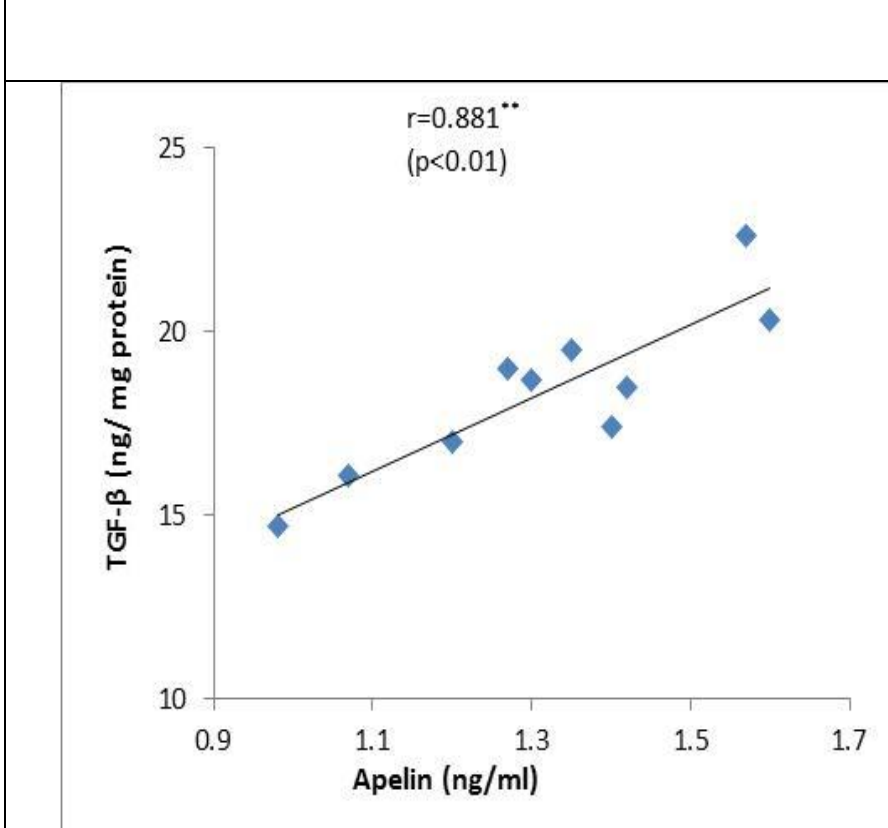

C: Correlation between apelin serum level and hepatic TGF- $\beta$ in the BDL group.

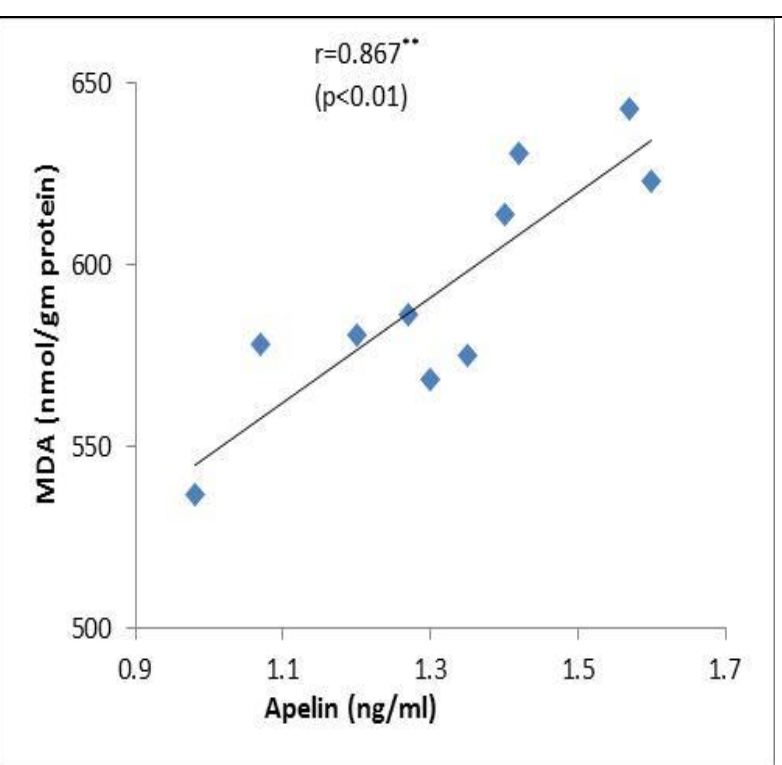

B: Correlation between serum Apelin and MDA levels in the BDL group.

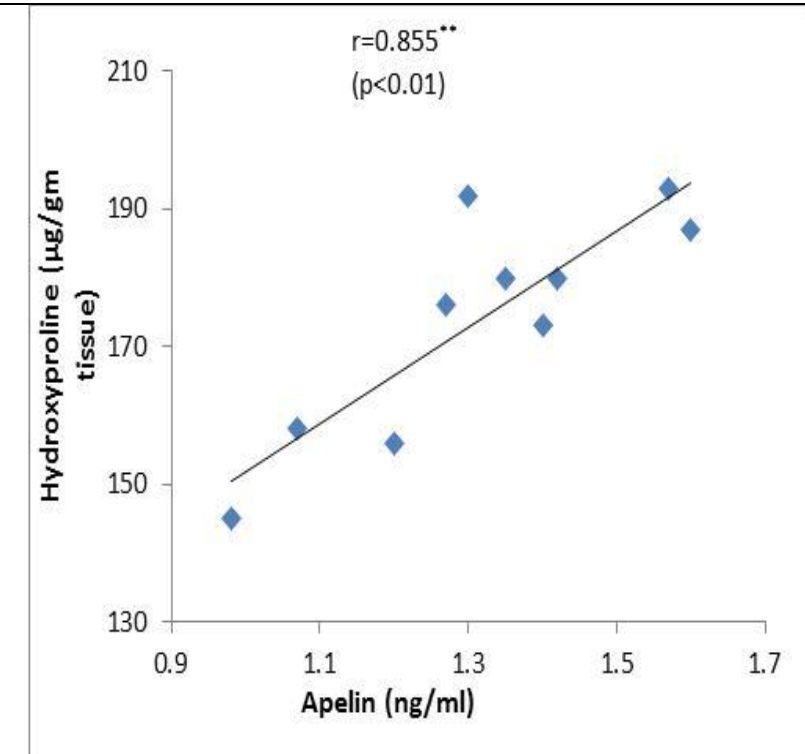

D: Correlation between apelin serum level and hepatic hydroxyproline content in the BDL group.

Figure (2) 


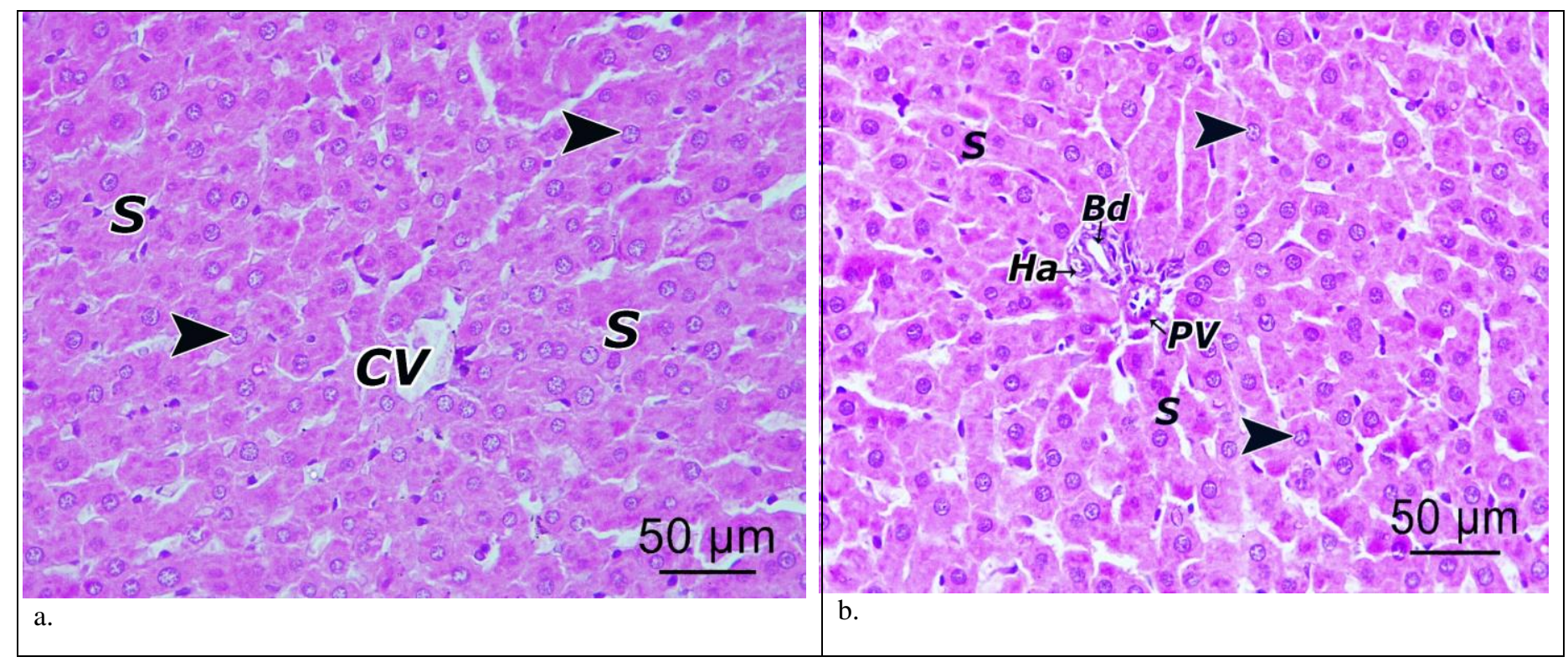

Figure (3)
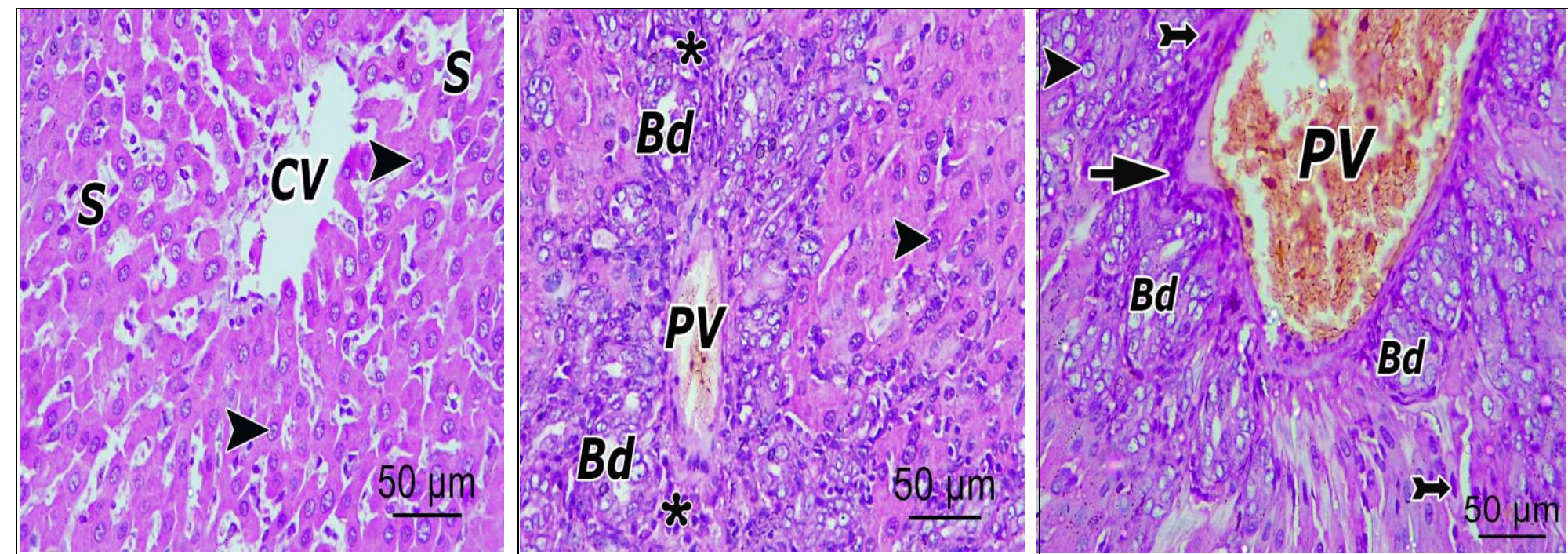
a.

b.

c.

Figure (4) 

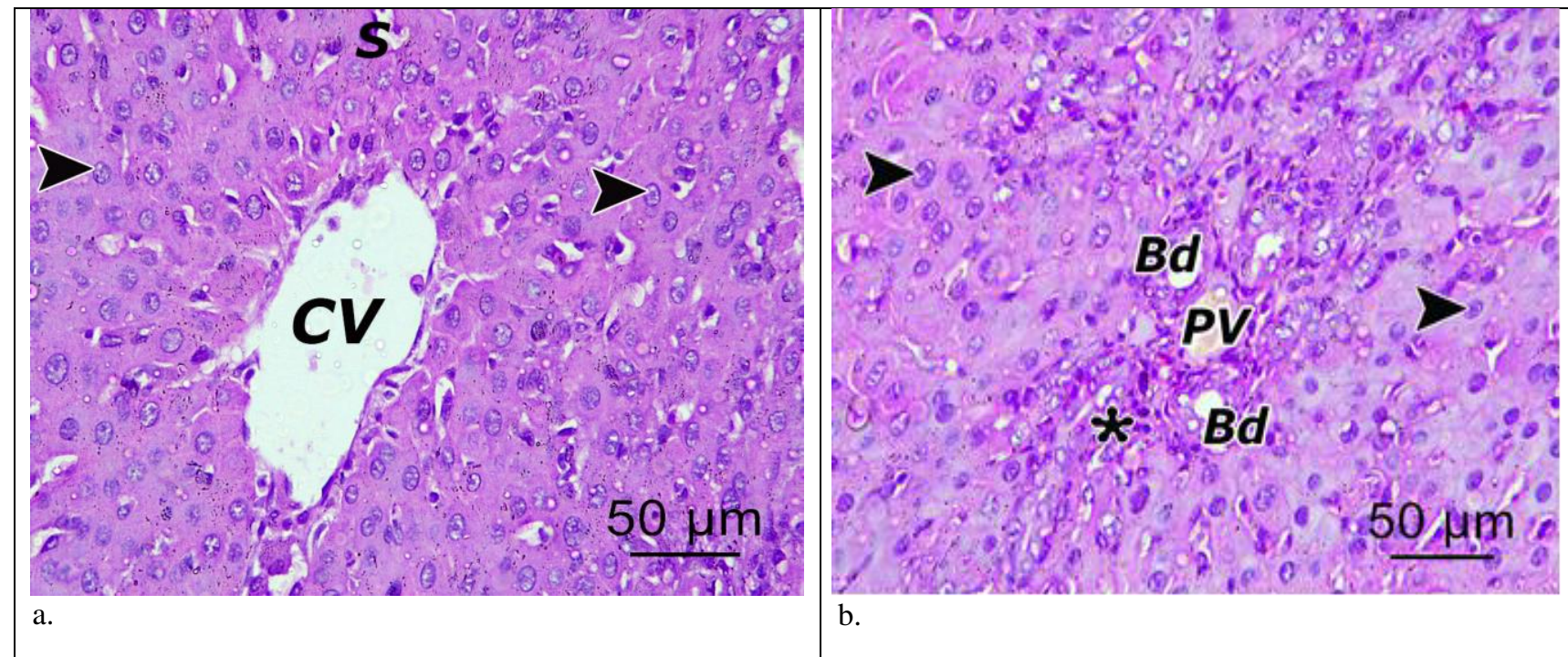

Figure (5)
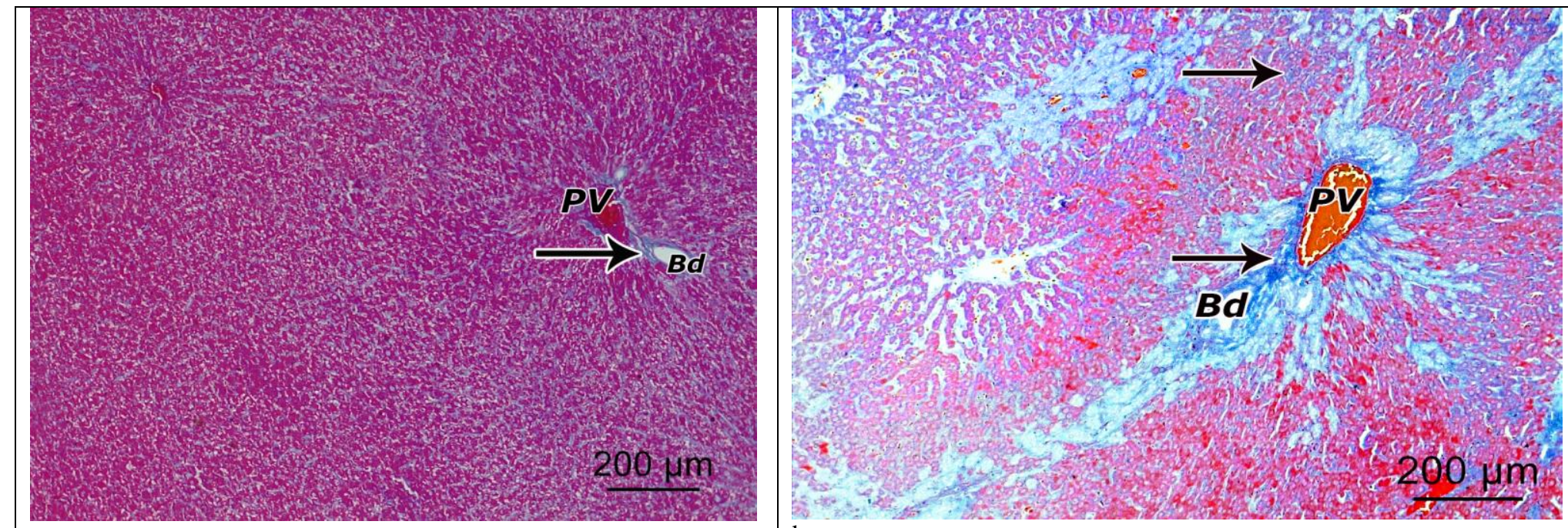

b
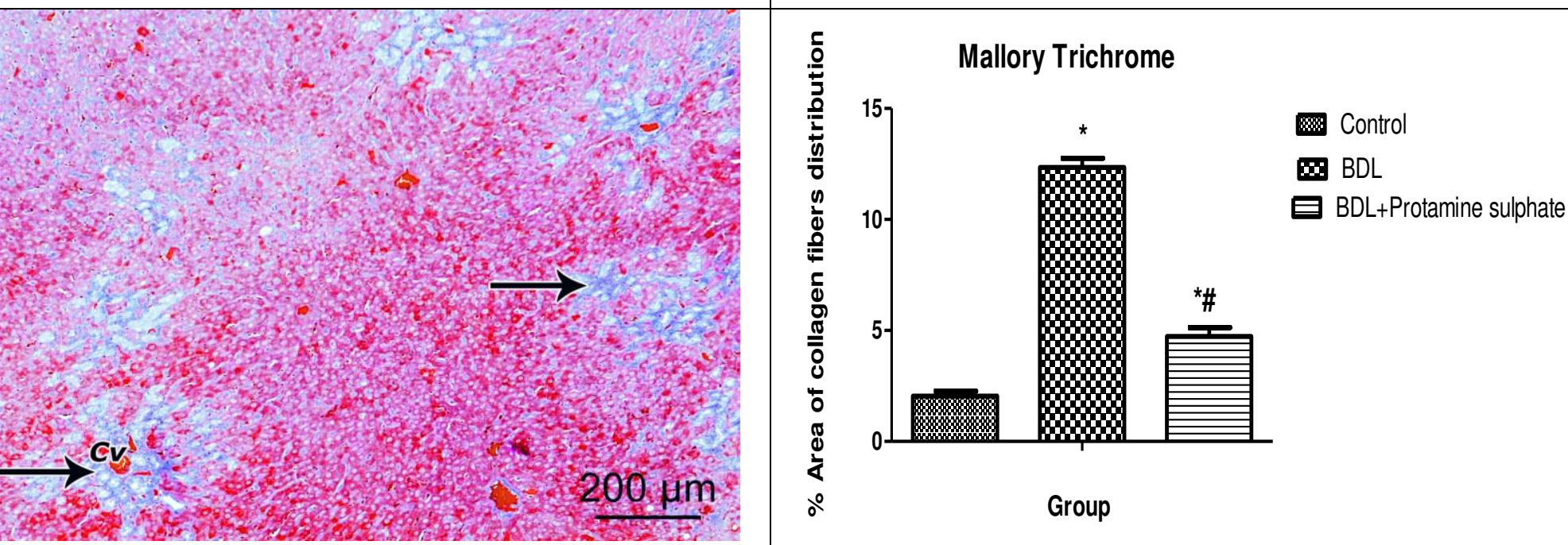

d. * (Significant versus control group), \# (significant versus BDL group)

Figure (6). 


\section{Supplementary Files}

This is a list of supplementary files associated with this preprint. Click to download.

- RawDataindex..pdf

- Supplementarytables.pdf 